\title{
FINANCIAMENTO EMPRESARIAL DE CAMPANHA ELEITORAL E POSTERIOR RELAÇÃO COM O GOVERNO ELEITO: DIRETRIZES PARA O SISTEMA PREVENTIVO DE INFRAÇÕES PENAIS ELEITORAIS E DO ENDÊMICO MODELO DE CORRUPÇÃO ${ }^{1}$
}

\author{
Corporate financing of electoral campaign and subsequent relationship with \\ the elected government: guidelines for the preventive system of electoral criminal \\ offenses and the endemic model of corruption
}

\section{Roberto Ferreira Archanjo da Silva}

Resumo: O presente trabalho visa a abordar de forma contextualizada o sistema eleitoral brasileiro, suas mazelas, peculiaridades legislativas, conquistas e as recentes discussões acerca do financiamento de campanhas eleitorais, o que diretamente nos remete ao estudo de condutas penalmente reprováveis realizadas no decorrer das atividades políticas, seja pelos partidos, seja pelos candidatos, seja até mesmos pelas entidades privadas que possuem interesses, por vezes, escusos, em patrocinar o pleito eleitoral. Quais são os limites ou controles necessários para legitimar a existência de subsídios públicos ou particulares em campanhas eleitorais? Diante de tantos escândalos envolvendo condutas corruptivas e imorais, é possível tornar o sistema de financiamento eleitoral eficiente? Tais pontos são discutidos na atual proposta de reforma política, e o presente estudo traz à tona a necessidade de estabelecermos diretrizes para o sistema preventivo de infrações penais eleitorais relacionadas ao financiamento de campanha e de práticas corruptas decorrentes de acordos com os financiadores. Além da transparência das atividades eleitorais, dos controles e limites rígidos de gastos, urge uma proposta de governo aberto e a própria efetivação da integridade empresarial, alteração recente no âmbito corporativo, mas que reflete na condução dos negócios e na cultura de combate à corrupção. Pela presente pesquisa, pode-se concluir que a existência de normas que regulam o sistema eleitoral não é suficiente para abranger a complexidade de atividades e agentes envolvidos no tema, o que torna necessária a criação de efetivos controles e demonstrações claras para a sociedade acerca da destinação da verba empregada, como forma inclusive de repudiar atos que sejam indecorosos e incoerentes com as ideias de Democracia e Cidadania. A educação é fundamental para desenvolver a cultura da intolerância à corrupção. A fim de assegurar a lisura do financiamento empresarial de campanha eleitoral e de evitar a prática da corrupção pelo doador em conjunto com o candidato eleito, o ordenamento jurídico brasileiro deve exigir que a empresa doadora comprove a efetividade do programa de integridade. A técnica de pesquisa é a documentação indireta, que abrange a pesquisa documental e bibliográfica. Esta permite o resgate factual e teórico das peculiaridades do financiamento empresarial de campanha eleitoral, por meio do confronto entre as correntes dogmáticas que formam os pilares centrais de sustentação das teses defendidas. Os métodos de procedimento utilizados são o histórico, o monográfico e o estático. O eixo fundamental da pesquisa está no método empírico-dialético, como arte de solucionar o problema, pautada na realidade (experiência jurídica) e no conhecimento do Direito em dado momento histórico. Em complementação, adota-se o método técnico-jurídico, mediante as concepções valorativas e sociais, para compreender o sentido dos enunciados normativos.

Palavras-chave: Financiamento de campanha eleitoral. Crimes eleitorais. Corrupção. Governo aberto. Transparência. Programa de Compliance.

${ }^{1}$ O presente tema foi exposto nas "Primeras Jornadas Binacionales de Derecho Comparado - Derechos Politicos e Instituciones Electorales”. Facultad de Derecho Universidad Nacional de Cuyo, Argentina, 16 de mayo de 2017.

Artigo recebido em 8 set. 2017 e aprovado em 12 nov. 2018. 


\begin{abstract}
The present work aims to approach in a contextualized way the Brazilian electoral system, its ills, legislative peculiarities, achievements and the recent discussions about the financing of electoral campaigns, which directly refers us to the study of criminally reprehensible conduct carried out in the course of political activities, whether by parties, candidates or even by private entities that have vested interests, sometimes, to sponsor the electoral process. What are the limits or controls necessary to legitimize the existence of public or private subsidies in electoral campaigns? In the face of so many scandals involving corrupt and immoral conducts, is it possible to make the electoral financing system efficient? These points are discussed in the current proposal for political reform and the present study brings out the need to establish guidelines for the preventive system of electoral criminal offenses related to campaign financing and corrupt practices resulting from agreements with donors. In addition to the transparency of electoral activities, controls and rigid spending limits, a proposal for open government and the very effectiveness of corporate integrity, a recent change in the corporate sphere, but reflected in the conduct of business and in the anti-corruption culture. By the present research it can be concluded that the existence of norms that regulate the electoral system is not sufficient to cover the complexity of activities and agents involved in the subject, which makes necessary to create effective controls and clear demonstrations for the society about the destination of the money used, as a way of repudiating acts that are unseemly and incoherent with the ideas of Democracy and Citizenship. The education is extremely necessary to develop an anticorruption culture. In face to persecute an ethical way to subsidies the electoral campaigns by corporates and avoid the corruption practices by the sponsors, the Brazilian law needs to input the obligation for the companies that wants to donate to comprove the effectiveness of their compliance programs. The research technique is indirect documentation, which covers documentary and bibliographic research. This allows the factual and theoretical rescue of the peculiarities of the business financing of the electoral campaign, by means of the confrontation between the dogmatic currents that form the central pillars of sustentation of the defended theses. The procedure methods used are historical; monographic and; static. The fundamental axis of research is in the empirical-dialectical method, as an art of solving the problem, based on reality (legal experience) and on the knowledge of law at a given historical moment. In addition, the technical-legal method is adopted, through valuation and social conceptions, to understand the meaning of normative statements.
\end{abstract}

Keywords: Electoral campaign financing. Electoral crimes. Corruption. Open government. Transparency. Compliance program. 


\section{Introdução}

A democracia foi retratada na Antiguidade como forma de governo. No século XIX, porém, foi considerada pelo marxismo como forma de governo da burguesia, o que a reduziu à mera ideologia.

Contudo, a História demonstra que a humanidade sofreu e sofre com governos que utilizam o poder para perseguir opositores, dominar a população por meio do medo e da limitação extrema da liberdade. Para isso, rompem com a democracia e adotam formas autoritárias de governar.

Esse problema é potencializado na sociedade contemporânea por diversos fatores, como a intolerância em suas diferentes faces (religiosa, geográfica, política, social, etc.), as relações entre os Estados soberanos e os povos no mundo globalizado, tensionadas pelo compartilhamento de problemas, entre eles a imigração, o refúgio, a pobreza, as guerras civis, as intervenções militares com interesses econômicos, as questões climáticas e o desmatamento.

Com isso, as pessoas sentem a necessidade de governos democráticos, ainda que não saibam exatamente o que essa expressão significa. Esse fenômeno "psicológico" cresceu no Brasil na década de 1980 e foi materializado no movimento das "Diretas Já", que resultou na promulgação da Constituição da República Federativa do Brasil em 5 de outubro de 1988. Portanto, temos a certeza de que a democracia foi uma conquista do povo brasileiro.

Acontece que o Brasil passa por crises econômicas e éticas que facilitam o crescimento do pensamento popular pelo regresso ao autoritarismo. Esse fenômeno não é exclusivamente nosso, mas de movimentos de extrema direita, que clamam por um "salvador da pátria", com perfil austero e patriótico para reorganizar a gestão pública.

Assim, surgem ameaças à democracia e ao Estado de Direito que podem resultar em medidas extremas para obter rápidos resultados, cujas condutas, no mais das vezes, não observam os limites constitucionais e legais sob a justificativa da eficiência.

Sem dúvida, a democracia não se resume ao direito de votar e ser votado. O exercício da democracia exige muito mais, conforme veremos adiante, mas a sua manutenção depende desse modelo de escolha dos representantes. Ocorre que o pleito eleitoral tem um custo financeiro bilionário em qualquer nação soberana, e o dilema mundial é: quem deve pagar a conta?

Resenha Eleitoral (Florianópolis), v. 22, n. 1-2, p. 77-106, 2018 
No Brasil, a conta sempre foi paga pela sociedade, por meio de doações pessoais e empresariais. Estas foram reputadas como injustas pelo Supremo Tribunal Federal porque reduzem as chances dos candidatos que não têm o apoio empresarial, além dos problemas éticos e penais no âmbito das próprias empresas que foram expostos ao público com o julgamento da ação penal 470, caso conhecido como "Mensalão", e com as diversas etapas da "Operação Lava-Jato" no âmbito da Justiça Federal e dos Tribunais.

O presente artigo tem o propósito de enfrentar os problemas relacionados ao financiamento empresarial de campanha eleitoral, especificamente sobre a imoralidade e a corrupção empresarial e política.

Assim, desponta como problema a ser solucionado o seguinte questionamento: Quais os instrumentos adequados para assegurar a transparência na relação entre as empresas e os candidatos no pleito eleitoral e, posteriormente, com o governo?

Muitos desses instrumentos existem e podem direcionar as empresas, os candidatos e o governo para assegurar que as relações sejam éticas e lícitas, por meio de um sistema de controle efetivo, transparente e desburocratizado. Mas, devem ser organizados no sistema normativo, conforme o sistema jurídico que ora se propõe.

\section{O que é democracia na República Federativa do Brasil?}

A compreensão do significado de democracia é necessária para estabelecer as diretrizes do sistema preventivo de infrações penais eleitorais e concorrências em decorrência do financiamento empresarial de campanha eleitoral.

Embora o objeto de estudo seja a democracia, compartilhamos da advertência de Paulo Bonavides sobre a relevância do Estado de Direito, que parece uma utopia dos demagogos na sociedade contemporânea: "É como a democracia, a liberdade, às vezes o próprio Direito: certas pessoas só os reconhecem e estimam depois de violados ou conculcados, ou seja, durante a repressão, a ditadura ou o terror.” (BONAVIDES, 2007, p. 303).

Assim como a democracia, o Estado de Direito, independentemente dos conceitos estabelecidos pelos pensadores, caracteriza uma noção que o povo sente e compreende (BONAVIDES, 2007, p. 203).

Convém esclarecer que não se pretende debater o significado de democracia sob os pontos de vista ocidentais e orientais, tampouco sob as 
óticas social e liberal. Mas, somente, destacar três características relacionadas ao exercício do poder pelo povo ou em seu nome, que podem ser cumulativas, a fim de identificar o modelo adotado pela República Federativa Brasil, formalmente definida como um "Estado Democrático de Direito" no artigo 1ำ de sua Constituição, para, ao final, identificar um ponto marcante da democracia brasileira.

A democracia direta assegura a participação de todos os cidadãos no processo de tomada de decisões. Esse modelo foi adotado na Antiguidade, mas em sociedades massificadas é impossível reunir a maioria das pessoas em assembleia para tomar as decisões políticas.

$\mathrm{Na}$ democracia representativa, embora o poder político emane do povo, será exercitado pelos representantes eleitos por meio do voto direto e secreto. Por ocasião do exercício do poder constituinte originário, optou-se por uma democracia representativa, ao estabelecer que o poder popular deve ser exercido "por meio de representantes eleitos" . A fim se assegurar a democracia representativa, o artigo $1^{\circ}$ da Constituição da República Federativa do Brasil define como um dos fundamentos do Estado Democrático de Direito o pluralismo político.

Entre os direitos políticos dos cidadãos, destaca-se o sufrágio universal, por meio do voto direto e secreto (conferido, inclusive, aos analfabetos). Também são definidas as regras sobre quem pode votar, de forma obrigatória ou facultativa, as condições de elegibilidade, entre outras disposições no artigo 14 da Constituição da República.

Diversos direitos fundamentais, decorrentes das conquistas da humanidade, são estabelecidos, tanto no âmbito nacional como no cenário internacional.

Jorge Miranda (2009, p. 214) destaca as características da democracia participativa na Constituição brasileira como os mecanismos de participação popular denominados plebiscito, referendo e iniciativa popular.

Essa democracia, embora assegure aos cidadãos a participação direta na tomada de decisão, serve, no mais das vezes, para legitimar um governo autoritário por meio de consultas plebiscitárias, o qual manipula o povo com discursos populistas, cujos resultados são afirmativos, geralmen-

\footnotetext{
${ }^{2}$ Constituição da República Federativa do Brasil, artigo 1, parágrafo único: “Todo o poder emana do povo, que o exerce por meio de representantes eleitos ou diretamente, nos termos desta Constituição."
}

Resenha Eleitoral (Florianópolis), v. 22, n. 1-2, p. 77-106, 2018 
te acima de 90\%, como ocorre desde os romanos na Antiguidade, na França de Napoleão, desembocando nas ditaduras ideológicas do século XX que se valeram de plebiscitos, como Stalin, Mussolini e Hitler. Essas consultas podem servir para tornar ilimitados os poderes do governante, executar um golpe de Estado (BONAVIDES, 2007, p. 311-312), entre outras medidas autoritárias.

Por isso, a democracia semidireta, como forma de consulta popular, deve ser exercida somente em períodos de estabilidade política, econômica, jurídica e social, nos quais as liberdades jurídicas são concretamente asseguradas, como os direitos de manifestação do pensamento, reunião, expressão política e ideológica, entre outros direitos fundamentais.

Além dessas características, existe no Brasil um importante instrumento de controle do poder público e de acesso à justiça, especialmente por isentar o autor de custas judiciais e de sucumbência, típico de uma democracia participativa, denominado ação popular ${ }^{3}$, a fim de assegurar o pleno exercício da cidadania, da moralidade pública e da preservação do patrimônio público, histórico e cultural. Isto é, ao lado do Ministério Público, qualquer cidadão pode impugnar, perante o Poder Judiciário, os atos da administração pública reputados como lesivos à coisa pública e aos direitos difusos.

Portanto, a democracia brasileira é representativa e participativa. Convém observar que a democracia não se resume às formas de exercer o poder, especificamente o direito de escolher os representantes e de exercer a cidadania por meio dos instrumentos que asseguram a participação popular. Significa, acima de tudo, o respeito aos direitos fundamentais, à promoção dos direitos sociais e da paz.

Caso tais direitos sejam violados, as garantias constitucionais e aquelas estabelecidas em Tratados Internacionais sobre Direitos Humanos servem para o Poder Judiciário corrigir as ilegalidades e coibir os abusos de poder, até mesmo em decorrência da inevitabilidade do controle jurisdicional, pois nenhuma lesão ou ameaça de lesão será excluída de apreciação judicial. Inevitavelmente, o conceito de cidadania foi ampliado para consi-

\footnotetext{
${ }^{3}$ Constituição da República Federativa do Brasil, artigo 5으. LXXIII: “qualquer cidadão é parte legítima para propor ação popular que vise a anular ato lesivo ao patrimônio público ou de entidade de que o Estado participe, à moralidade administrativa, ao meio ambiente e ao patrimônio histórico e cultural, ficando o autor, salvo comprovada má-fé, isento de custas judiciais e do ônus da sucumbência".
} 
derar toda pessoa, independentemente da possibilidade de exercer plenamente os direitos políticos, como sujeito de direitos e deveres, isto é, como cidadão inserido na sociedade (SILVA apud SILVA; MIRANDA, 2009, p. 224).

Ocorre que, no Brasil, esse modelo constitucional de democracia está ameaçado por movimentos antidemocráticos, eventuais e oportunistas, que utilizam as crises econômica e política, por meio de manifestações de grupos que clamam pela intervenção militar, como se fosse possível esquecer a própria história - os 20 anos de ditadura militar no Brasil. Os direitos conquistados pela humanidade, especialmente as liberdades jurídicas, como o direito de manifestação do pensamento, inclusive utilizado pelos próprios movimentos antidemocráticos, são cumulativos e não podem retroagir.

\section{Sistema eleitoral brasileiro}

O regime político brasileiro, como destacado alhures, está fundamentado na democracia, em que o povo elege quem serão os seus governantes. Fundamenta-se, ainda, no sistema presidencialista, que é composto por três poderes autônomos: Executivo, Legislativo e Judiciário ${ }^{4}$.

O sistema eleitoral é baseado no voto direto (e secreto), ou seja, o eleitor vota diretamente no candidato ao cargo a ser preenchido, por escrutínio secreto 5 . Porém, esse sistema é composto por dois subsistemas eleitorais, denominados majoritário e proporcional.

No primeiro subsistema, é consagrado o candidato que obtiver a maioria dos votos para os cargos (majoritários) de Presidente da República, governadores, senadores e prefeitos ${ }^{6}$.

No subsistema proporcional, o número de representantes políticos é distribuído proporcionalmente entre os partidos políticos concorrentes. Assim, o preenchimento de cargos é calculado pelo quociente eleitoral (número de votos válidos dividido pelo número de vagas a serem preenchidas) e partidário (número de votos válidos recebidos pelo partido dividido pelo quociente eleitoral). Esse cálculo está previsto na Resolução no 23.456, de 15 de dezembro de 2015 do Tribunal Superior Eleitoral (TSE) ${ }^{7}$.

\footnotetext{
${ }^{4}$ Disponível em: <http://www.brasil.gov.br/governo/2010/09/processo-eleitoral>. Acesso em: 27 ago. 2017.

${ }^{5}$ Idem.

${ }^{6}$ Idem.

${ }^{7}$ Disponível em: <http://www.tse.jus.br/imprensa/noticias-tse/2016/Setembro/saiba-como-calcular-os-quocientes-eleitoral-e-partidario-nas-eleicoes-2016>. Acesso em: 8 set. 2017.
}

Resenha Eleitoral (Florianópolis), v. 22, n. 1-2, p. 77-106, 2018 
Cumpre esclarecer sobre este ponto que, no Brasil, os votos são direcionados ao partido que recebe as vagas, e não aos candidatos, ou seja, no exercício do direito ao voto o cidadão acredita escolher o candidato (pessoa), quando na verdade participa da escolha dos partidos que integrarão o governo, ao tratar da eleição de deputados Federais, deputados Estaduais/Distritais e vereadores.

\subsection{Aspectos eleitorais na Constituição da República}

A Constituição da República Federativa do Brasil de 1988 prevê em seu artigo $1^{\circ}$ como princípios fundamentais da República a soberania, a cidadania, a dignidade da pessoa humana, os valores sociais do trabalho e da livre iniciativa e o pluralismo político, destacando, em seu parágrafo primeiro, que todo o poder emana do povo que o exerce, como observado alhures, por meio de representantes eleitos ou diretamente (geralmente de forma subsidiária).

Ainda com relação ao exercício dos poderes políticos, o legislador constituinte destaca no artigo 14 da Constituição da República as condições e os requisitos para operacionalização da soberania popular por meio de representantes eleitos, estabelecendo a forma de alistamento eleitoral, as condições de elegibilidade, além de dispor mais adiante sobre a criação, a fusão, a incorporação e a extinção de partidos políticos, bem como a forma de prestação de contas e outras obrigações inerentes à atividade partidária.

O texto constitucional discorre também sobre a criação da Justiça Eleitoral $^{8}$, órgão de jurisdição especializada que integra o Poder Judiciário e cuida da organização do processo eleitoral, a fim de garantir o respeito à soberania popular e à cidadania.

Os supramencionados dispositivos, de ordem constitucional, legitimam o sistema e o processo eleitoral brasileiro e garantem à sociedade segurança jurídica, tanto com relação à escolha de seus representantes, quanto a respeito da fiscalização necessária no decorrer das campanhas políticas e do cumprimento dos mandatos.

\subsection{Regramentos infraconstitucionais}

Além das normas constitucionais, integram o sistema normativo eleitoral outras leis destacadas a seguir, que são responsáveis por regulamentar o cumprimento das premissas e garantias apresentadas pelo legislador constituinte.

\footnotetext{
${ }^{8}$ Artigos 118 a 121 da Constituição da República Federativa do Brasil.
} 
A Lei no 4.737, de 15 de julho de 1965 do Código Eleitoral, é composta de normas destinadas a assegurar a organização e o exercício de direitos políticos, precipuamente os de votar e ser votado.

Mesmo com a codificação, considerando a complexidade dos pleitos eleitorais, o sistema normativo eleitoral é amplo, o que dificulta a compreensão das regras e princípios e exige da Justiça Eleitoral a edição de Resoluções que antecedam as eleições para explicar o entendimento atual desse complexo sistema.

Podem ser destacadas as Leis nos 9.504, de 30 de setembro de 1997, que estabelece normas para as eleições; 9.096, de 19 de setembro de 1995, que dispõe sobre os partidos políticos, regulamentando os artigos 17 e 14, S 3ㅜ, V, da Constituição da República; 13.165, de 29 de setembro de 2015, que altera as Leis nos 9.504/1997, 9.096/1995 e o Código Eleitoral, para reduzir os custos das campanhas eleitorais, simplificar a administração dos Partidos Políticos e incentivar a participação feminina.

A regulamentação dos dispositivos constitucionais por meio dos regramentos infraconstitucionais, embora necessária, a fim de adequar o ordenamento jurídico à realidade social, não deve ser excessiva, como ocorre com o sistema normativo eleitoral brasileiro, que muitas vezes se mostra incompreensível e ineficiente.

\subsection{O processo de escolha dos representantes}

O processo eleitoral no Brasil compreende as fases organizativas das eleições, sistematizado pela Justiça Eleitoral, em nível municipal, estadual e federal ${ }^{9}$.

Na esfera federal, a Justiça Eleitoral possui como órgão máximo o Tribunal Superior Eleitoral (TSE) e, em cada Estado da Federação e no Distrito Federal, há um Tribunal Regional Eleitoral (TRE), bem como juízes e juntas eleitorais ${ }^{10}$.

A Justiça Eleitoral organiza, fiscaliza e realiza as eleições regulamentando o processo eleitoral, examinando as contas de partidos e candidatos em campanhas, controlando o cumprimento da legislação pertinente em período eleitoral e julgando os processos relacionados com as eleições ${ }^{11}$.

\footnotetext{
${ }^{9}$ Disponível em: <http://www.tse.jus.br/eleicoes/processo-eleitoral-brasileiro/funcionamento-do-processo-eleitoral-no-brasil>. Acesso em: 27 ago. 2017.

${ }^{10}$ Idem.

${ }^{11}$ Idem.
}

Resenha Eleitoral (Florianópolis), v. 22, n. 1-2, p. 77-106, 2018 
Embora as etapas de votação, totalização e divulgação dos resultados sejam as mais conhecidas, o processo eleitoral possui outras fases muito importantes como o cadastro eleitoral, a etapa de candidaturas, a prestação de contas e a logística eleitoral. Além disso, há ainda a fase de pós-eleições, que compreende, entre outras atividades, a diplomação dos eleitos ${ }^{12}$.

A votação compreende o momento em que os representantes do povo são eleitos pelo povo, por isso, é a fase do processo eleitoral mais conhecida pelos cidadãos ${ }^{13}$.

A Justiça Eleitoral brasileira demonstra recorrente preocupação com a organização dos pleitos eleitorais, por isso, utiliza os recursos tecnológicos para torná-los seguros e eficientes, por meio da adoção de urnas eletrônicas, sistema inviolável de apuração dos votos e da identificação dos eleitores por meio do leitor biométrico.

Quando o processo de votação nas seções é finalizado, os dados são assinados digitalmente, gravados em uma mídia de resultado e encaminhados ao local próprio para transmissão ${ }^{14}$. No caso das localidades de difícil acesso, como aldeias indígenas e comunidades ribeirinhas, a transmissão é feita via satélite para o respectivo Tribunal ou zona eleitoral.

Depois de receber os dados, os Tribunais Regionais Eleitorais dão início ao procedimento de totalização dos votos (soma de todos os boletins de urna) e, em seguida, à divulgação dos resultados ${ }^{15}$.

O processamento das informações de uma eleição - com exceção dos resultados para o cargo de presidente da República - é feito no Tribunal Regional Eleitoral. A partir deste ponto, o sistema de divulgação dá publicidade ao número de votos para governador, senador, deputado federal, deputado estadual/distrital, prefeito e vereador ${ }^{16}$.

No caso de presidente da República, o Tribunal Superior Eleitoral faz tanto a totalização quanto a divulgação dos resultados. Além disso, celebra parcerias com veículos de comunicação (internet, rádio, TV, impresso) para divulgar as eleições e disponibiliza softwares que permitem ao usuário acompanhar a publicação dos resultados em tempo real ${ }^{17}$.

\footnotetext{
${ }^{12}$ Idem.

${ }^{14}$ Idem.

${ }^{15}$ Idem.

${ }^{16}$ Idem.

${ }^{17}$ Idem.
}

13 Disponível em: <http://www.tse.jus.br/eleicoes/processo-eleitoral-brasileiro/votacao-totalizacao-e-divulgacao-das-eleicoes/totalizacao-dos-resultados-das-eleicoes>. Acesso em: 27 ago. 2017. 
O sistema eleitoral brasileiro apresenta inovações tecnológicas que contribuem para o exercício da cidadania. Entretanto, como se verá adiante, o que se propõe discutir e trazer à reflexão com esta pesquisa são as formas de financiamento empresarial de campanha eleitoral, ou seja, como os candidatos e partidos captam recursos financeiros da sociedade, o que por vezes reflete na prática de condutas imorais e penalmente reprováveis e que trazem à tona o questionamento acerca da legitimidade desses processos.

\section{Os principais problemas decorrentes do financiamento empresarial de campanha eleitoral}

No presente tópico, os principais problemas decorrentes do financiamento empresarial de campanha eleitoral no Brasil serão destacados e as consequências jurídicas que culminaram na proibição dessa prática a partir de 2015, inicialmente por decisão do Supremo Tribunal Federal e, posteriormente, por modificação legislativa.

Parte dos problemas, embora antigos, vieram à tona com a descoberta do sistema endêmico de corrupção dos governantes pelos empresários que financiam desde as campanhas eleitorais até os desejos luxuosos dos detentores do poder e de seus familiares.

Surgem, surpreendentemente, manifestações de tolerância com atos de corrupção, como fossem condutas necessárias e éticas para realizar uma campanha eleitoral. Conferem um significado elástico à palavra "ética", que pode ser definida como uma "ética da conveniência" (CORTELLA; BARROS FILHO, 2014, p. 9).

O custo das campanhas eleitorais aflora como o elemento justificador de práticas ilícitas e imorais de determinados candidatos, empresários e governantes, que ajustam uma retribuição futura na hipótese de vitória eleitoral, geralmente, asseguram a conquista de contratos vultuosos com a Administração Pública, por meio de processos concorrenciais sem lisura, com o sacrifício dos concorrentes e com o fornecimento de informações privilegiadas.

A campanha eleitoral de 2014 destinada à escolha de Presidente da República, Governadores e respectivos vices, além de Deputados Estaduais e Distritais, bateu recorde histórico, pois custou aproximadamente cinco bilhões de reais, dos quais cerca de 60\% dos gastos foram realizados pelos três maiores partidos do país. As principais despesas foram com publicida- 
de, impressão de material gráfico e apresentações no horário eleitoral. O Partido dos Trabalhadores e o Partido Social Democrata do Brasil gastaram, em média, um milhão de reais por cargo eletivo (TERENZI; URIBE; AZEVEDO, 2014).

As eleições de 2016 tiveram gastos mais modestos, cerca de dois bilhões, cento e trinta e um milhões de reais (CASTRO, 2016), como reflexo da proibição do financiamento empresarial de campanha eleitoral e da desestabilização de grandes empresas que financiavam, também ilegalmente, as principais campanhas eleitorais, por meio das operações da Polícia Federal nos últimos anos, com o auxílio do Ministério Público Federal e a autorização do Poder Judiciário, que resultaram nas prisões de expressivos empresários, ocupantes e ex-ocupantes de cargos eletivos, funcionários públicos e pessoas envolvidos com atos de corrupção.

Ocorre, portanto, que muitas empresas utilizaram o financiamento clandestino de campanhas eleitorais, e muitos candidatos se beneficiaram do sistema, com distribuições e recebimentos de valores e serviços não contabilizados, tampouco, declarados. Por isso, os gastos das campanhas eleitorais são muito superiores aos apurados oficialmente.

\subsection{Financiamento empresarial clandestino de campanha elei- toral ("caixa dois")}

Como visto, para se eleger no Brasil, não basta ser popular ou apresentar propostas de interesse da maioria da sociedade: é preciso gastar muito dinheiro.

Ocorre que as remunerações dos cargos eletivos são incapazes de repor as vultuosas quantias gastas nas eleições. Levando em consideração o cenário econômico brasileiro, as pessoas físicas também não possuem capacidade econômica para financiar os elevados custos das campanhas eleitorais. Até as empresas deveriam observar os limites legais e as regras internas sobre as doações.

Com isso, popularizou-se a prática do financiamento empresarial clandestino de campanhas eleitorais, com distribuições e recebimentos de valores e serviços não contabilizados e não declarados, popularmente conhecido como "caixa dois" para campanha eleitoral.

A prática foi detalhada em colaboração premiada prestada por um dos sócios de uma grande empreiteira brasileira, que admitiu que três 
quartos dos financiamentos de campanhas eleitorais eram clandestinos e os financiamentos regulares eram tratados como "bônus" (CARAZZAI, 2017), o que demonstra a excepcionalidade do cumprimento da lei para muitas empresas envolvidas nos casos de fraudes e corrupções para obter vantagens indevidas perante a Administração Pública.

Aqueles que recebem doações eleitorais clandestinas podem se tornar inelegíveis por abuso de poder econômico ou político, corrupção ou fraude, conforme estabelece a Constituição da República ${ }^{18}$ e a Lei $\mathrm{n}^{\mathrm{o}}$ $9.504 / 1997^{19}$. O instrumento jurídico para responsabilizar o candidato é a ação de impugnação de mandato eletivo e não se confunde com o recurso contra a diplomação previsto no artigo 262 do Código Eleitoral, cujos fundamentos são diferentes, embora os fins sejam idênticos (COSTA, 2004, p. 190; 224).

Essa conduta causa prejuízos imensuráveis à democracia e ao povo brasileiro, corrói a lisura do processo eleitoral, impede que os demais candidatos concorram com as mesmas oportunidades, transforma os adversários em inimigos, pois muitos são dizimados politicamente, torna a alternância de poder uma ficção, facilita a manipulação das massas por meio da poderosa publicidade, propicia o estabelecimento de uma ditadura legitimada pelo povo. Esses bens jurídicos fundamentais são lesionados e estão concretamente ameaçados pelo financiamento empresarial clandestino de campanha eleitoral. Constata-se que ramos extrapenais são insuficientes para tutelá-los, por isso, a intervenção penal é necessária e adequada - está legitimada ${ }^{20}$.

A dogmática orienta que a repressão penal para salvaguardar a lisura do processo eleitoral exige uma ação prospectiva a fim de evitar fatos futuros (PONTE, 2008, p. 47), sem, contudo, estabelecer um direito penal do inimigo.

\footnotetext{
${ }^{18} \mathrm{O}$ mandato pode ser impugnado no prazo de 15 dias contados da diplomação, e a ação

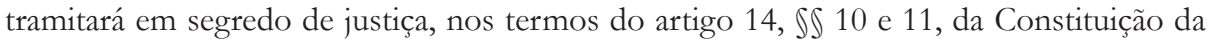
República.

${ }^{19}$ Vide artigos 73 a 78, da Lei no 9.504/1997.

${ }^{20}$ Luiz Carlos dos Santos Gonçalves (2012, p. 3) afirma que a regularidade das eleições e dos atos preparatórios para realizá-las são bens jurídicos "que assumem dignidade penal, ou seja, um grau de lesão ou ameaça suficiente a um bem jurídico, suficiente para autorizar o emprego de sanções penais e não meramente administrativas".
}

Resenha Eleitoral (Florianópolis), v. 22, n. 1-2, p. 77-106, 2018 
Pode ser que nem todo financiamento de campanha eleitoral por "caixa dois" caracterize uma corrupção, mas não deixa de ser uma infração penal eleitoral.

Assim, imperioso destacar que essa prática de financiamento de campanha eleitoral aflora criminosa, embora não tipificada com a rubrica de "caixa dois". Caracteriza, no mínimo, o delito de falsidade ideológica eleitoral, previsto no artigo 350 do Código Eleitoral ${ }^{21}$, desde que constate a potencialidade lesiva no documento objeto da falsidade (GOMES, 2010, p. 280), ou seja, deve ao menos ameaçar o pleito eleitoral.

Como o debate político enveredou para a questão da corrupção, convém esclarecer que a omissão da empresa sobre o financiamento de campanha eleitoral caracteriza o descumprimento de uma obrigação estabelecida na legislação eleitoral, especificamente no artigo $23, \$ 4^{\circ}$, da Lei $n^{2}$ 9.504/1997, que exige a emissão de recibo eleitoral, além das obrigações fiscais que requerem a declaração no imposto de renda. Logo, a informação deveria constar em documentos particular e público, cuja conduta se amolda ao comportamento (omissivo) penalmente relevante, previsto no artigo 350 do Código Eleitoral.

Caso a empresa financie parte da campanha eleitoral conforme as regras eleitorais e a outra parte sem contabilizar nem declarar, também estará caracterizado o descumprimento da obrigação eleitoral, e a conduta se amoldará ao referido tipo penal incriminador, pois inseriu "declaração falsa ou diversa da que devia ser escrita, para fins eleitorais".

Para essas condutas omissivas o Código Eleitoral estabelece a pena de reclusão de $u^{22}$ a cinco anos e multa quando a informação deveria constar em documento público, e de um a três anos e multa se deveria constar em documento particular. O Código confere tratamento mais severo, por meio de uma causa especial de aumento de pena, para o funcionário

${ }^{21}$ Código Eleitoral: Art. 350. Omitir, em documento público ou particular, declaração que dele devia constar, ou nele inserir ou fazer inserir declaração falsa ou diversa da que devia ser escrita, para fins eleitorais: Pena - reclusão até cinco anos e pagamento de 5 a 15 dias-multa, se o documento é público, e reclusão até três anos e pagamento de 3 a 10 dias-multa se o documento é particular. Parágrafo único. Se o agente da falsidade documental é funcionário público e comete o crime prevalecendo-se do cargo ou se a falsificação ou a alteração é de assentamentos de registro civil, a pena é agravada.

22 A maioria dos tipos penais eleitorais não indica a pena mínima porque o artigo 284 do Código Eleitoral dispõe o seguinte: "Sempre que este Código não indicar o grau mínimo, entende-se que será ele de quinze dias para a pena de detenção e de um ano para a de reclusão.” 
público infrator ou se o objeto da falsificação ou da alteração é assentamento de registro civil.

Além do delito anterior, outros podem estar ligados ao financiamento empresarial clandestino de campanha eleitoral, como o crime contra o sistema financeiro nacional em decorrência da manutenção ou da movimentação de valores paralelamente à contabilidade exigida pelo ordenamento jurídico ${ }^{23}$. Subsidiariamente, existe o crime contra a ordem tributária na hipótese de omissão que suprima ou reduza um tributo ${ }^{24}$.

Agora, passaremos aos destaques sobre as condutas corruptas, isto é, aquelas que essencialmente criam uma expectativa de contrapartida em decorrência do financiamento de campanha eleitoral.

\subsection{Corrupção eleitoral}

O Código Eleitoral e a legislação especial dispõem sobre os crimes eleitorais, que podem ser definidos como as "condutas descritas na lei como atentatórias à lisura, transparência, correta formação e desenvolvimento do processo eleitoral, cuja resposta penal destina a seus responsáveis a imposição da correspondente sanção penal” (PONTE, 2008, p. 18).

Essa espécie de criminalidade é classificada como de "plástico", pois possui vigência determinada (PONTE, 2008, p. 38), destina-se a proteger determinados bens jurídicos durante o pleito eleitoral.

Entre eles, destaca-se o crime de corrupção eleitoral, previsto no artigo 299 do Código Eleitoral ${ }^{25}$, que contempla as condutas do candidato para obter e do eleitor para dar voto em troca de vantagem.

Considerando a gravidade e a extensão do dano ao pleito eleitoral e aos alicerces do Estado Democrático de Direito, a punição para esse delito, estabelecida entre um e quatro anos de reclusão, recebe severas críticas, como exterioriza Antonio Carlos da Ponte, ao considerar que o mandado de criminalização para combater com eficiência a corrupção eleitoral foi parcialmente atendido porque o delito eleitoral mais grave conta com "uma

${ }^{23}$ Lei no 7.492/1986: Art. 11. Manter ou movimentar recurso ou valor paralelamente à contabilidade exigida pela legislação: Pena - Reclusão, de 1 (um) a 5 (cinco) anos, e multa. ${ }^{24}$ Vide artigo $1^{\circ}$ da Lei nº 8.137/1990.

${ }^{25}$ Código Eleitoral: Artigo 299. Dar, oferecer, prometer, solicitar ou receber, para si ou para outrem, dinheiro, dádiva, ou qualquer outra vantagem, para obter ou dar voto e para conseguir ou prometer abstenção, ainda que a oferta não seja aceita: Pena - reclusão até quatro anos e pagamento de cinco a quinze dias-multa.

Resenha Eleitoral (Florianópolis), v. 22, n. 1-2, p. 77-106, 2018 
pena pífia que, em tese, será descontada em regime aberto e, na quase integralidade das vezes, permitirá sua substituição por uma pena restritiva de direitos e multa, ou por duas penas restritivas de direitos" (PONTE, 2008, p. 166).

Mais do que isso, embora não seja uma infração penal de menor potencial ofensivo, é possível suspender condicionalmente o processo antes da instrução criminal definitiva, pois a pena mínima não ultrapassa o patamar de um ano, conforme dispõe o artigo 89 da Lei nº 9.099/1995.

Esse delito exige a expansão do Direito Penal, no sentido adotado por Jesús-María Silva Sánchez (2011), para majorar a pena estabelecida e prevenir, efetivamente, a prática da corrupção eleitoral.

\subsection{O modelo de corrupção endêmica}

O crescimento populacional desordenado, os recursos científicos e tecnológicos desenvolvidos nas últimas décadas, os fenômenos da globalização e da massificação agravam os problemas (BECK, 2010, p. 23) ${ }^{26}$ ou os tornam perceptíveis pela sociedade, potencializando a sensação de insegurança. Entre eles, destaca-se a corrupção em sentido amplo, entendida como todo ato no qual um dos interlocutores ou ambos, direta ou indiretamente, prometem, pactuam, oferecem, pedem, exigem o recebimento de vantagem indevida em prejuízo do Estado, nacional ou estrangeiro, ou até de particulares no âmbito privado conforme legislações estrangeiras, como a do Reino Unido, a da Alemanha, a da França, a da Itália e a da Espanha (GONTIJO, 2015, p. 84-146) e, por via reflexa, aplicável às corporações situadas no Brasil, que realizam transações internacionais. Vale observar que, no Brasil, existem propostas para tipificar o delito de corrupção no setor privado, como as contidas no Projeto de Código Penal e as no Projeto de Lei no 3.163 de 2015, que tramitam no Congresso Nacional.

Essas práticas demonstram o desvio de caráter dos agentes pela ganância e pela insensibilidade com as demais pessoas físicas e jurídicas que suportam indevidamente prejuízos em benefício dos corruptos. São perversas por causar prejuízos difusos e, no mais das vezes, elevados à população, que afetam diretamente serviços essenciais, como as prestações de serviços

\footnotetext{
${ }^{26}$ Ulrich Beck observa que, "na modernidade tardia, a produção social de riqueza é acompanhada sistematicamente pela produção social de riscos. Consequentemente, aos problemas e conflitos distributivos da sociedade da escassez sobrepõem-se os problemas e conflitos surgidos a partir da produção, definição e distribuição de riscos científico-tecnologicamente produzidos.” (BECK, 2010, p. 23).
} 
de saúde, educação, segurança pública, cultura, lazer, entre outros direitos dos cidadãos e deveres do Estado. Também causam prejuízos imensuráveis às corporações privadas, com danos à imagem e desfalques que podem colocar em risco a sobrevivência da empresa.

A corrupção corrói as instituições públicas e privadas, por meio das práticas imorais e ilegais em busca de ganhos indevidos, não só pelos prejuízos financeiros, mas também sob o ponto de vista da moral coletiva de determinada instituição, pois pessoas são arregimentadas para participarem de alguma forma das práticas corruptas. Assim, são formados grupos com divisão de tarefas para executar fraudes, facilitar ou desviar o trâmite de procedimentos e protocolos institucionais, apoderar-se de bens e valores, dividir os proveitos e os proventos. Com isso, o modelo de corrupção se instala nas instituições e as práticas se tornam reiteradas, por isso, é denominada como endêmica.

A corrupção na esfera penal possui significado próprio e bem mais estreito do que aquele de uso corrente. Existem delitos que são considerados corrupções pela sociedade, mas que recebem outras denominações jurídicas, como o de concussão (artigo 316 do Código Penal), que se caracteriza, em síntese, pela coação/intimidação, praticada por agente público que se vale dessa condição, para obter vantagem indevida. Conforme ver-se-á, esse comportamento é mais grave do que aqueles classificados pela legislação penal como corrupção.

Para caracterizá-la é preciso preencher os elementos de um dos tipos penais incriminadores relacionados aos comportamentos do particular (ativa) e/ou do funcionário público (passiva). O Código Penal brasileiro confere tratamento severo a ambas corrupções, com penas de reclusão de 2 a 12 anos, além da multa.

A corrupção na esfera penal não exige o estabelecimento de relação bilateral, isto é, não é imprescindível o acordo entre corruptor e corrupto. Então, a afirmação que só há corrupto porque existe o corruptor não é verdadeira. $\mathrm{O}$ agente pode ser corrupto sem que o particular aceite a proposta, conforme se verá.

A conduta corrupta do particular é definida pelo Código Penal como ativa, ainda que a iniciativa seja do funcionário público, desde que aceite a proposta. Neste caso, haverá uma promessa de pagamento capaz de 
caracterizar o delito. A corrupção ativa ${ }^{27}$ se caracteriza como a conduta de qualquer pessoa que oferece ou promete vantagem indevida a funcionário público, inclusive políticos eleitos, para praticar, deixar praticar, ou retardar ato de ofício (são aqueles que devem ser praticados independentemente de provocação). A oferta, se relacionada à vantagem indevida imediata, e a promessa, à vantagem indevida futura, na qual o agente procura celebrar um acordo com o funcionário público.

Quanto ao pacto celebrado entre os dirigentes ou colaboradores de empresas e os candidatos, caso se renove a partir da diplomação, ou seja, antes de assumir o cargo, responderão, respectivamente, por corrupções ativa e passiva. Caso a oferta seja apresentada no exercício do mandato, o particular também responderá por corrupção ativa. A pena do corruptor será majorada em um terço caso o candidato eleito ou alguém que integre o poder público retarde ou deixe de praticar o ato de ofício, ou, ainda, pratique infringindo qualquer regra do ordenamento jurídico.

Por outro lado, existia uma lacuna legislativa sobre a responsabilidade administrativa e civil das pessoas jurídicas pela prática de atos lesivos aos Estados nacional e estrangeiro, suprida pela Lei $\mathrm{n}^{-}$12.846, de $1^{\circ}$ de agosto de 2013 e pelo respectivo Decreto (regulamentar) no 8.420, de 18 de março de 2015. A seguir, trataremos das medidas que podem evitar ou reduzir as práticas corruptas no âmbito corporativo e preservar a lisura do pleito eleitoral.

Os comportamentos dos agentes públicos, entre eles os representantes eleitos pelo povo, independentemente do poder (legislativo, executivo e judiciário) e da esfera (federal, estadual e municipal), caso, em razão da função e partir da diplomação, receba, solicite ou celebre um acordo com particular a fim de obter uma vantagem indevida, responderá pelo delito de corrupção passiva $^{28}$, cujo tratamento penal, como destacado acima, é severo.

Mesmo assim, as práticas corruptas são constantes no Brasil, o que demonstra que o Direito Penal não é, e nem deve ser, o remédio de todos os males.

Agora, passaremos à análise dos limites ou controles necessários para legitimar a existência de subsídios públicos ou particulares em campanhas eleitorais, em busca de um sistema de financiamento eleitoral eficiente.

\footnotetext{
${ }^{27}$ Artigo 333 do Código Penal.

${ }^{28}$ Artigo 317 do Código Penal.
} 


\subsection{A reforma política: proibição do financiamento empresarial de campanha eleitoral}

Há 14 anos tramita na Câmara dos Deputados uma proposta de emenda constitucional (PEC 77/2003) para estabelecer alterações significativas no sistema eleitoral brasileiro, entre elas, uma sobre o financiamento de campanha eleitoral. Nos últimos meses, essa discussão ganhou maior relevância em razão da criação de uma comissão especial para discutir as principais mudanças sugeridas pelos partidos ${ }^{29}$.

Entre os pontos discutidos na referida reforma estão a redefinição do sistema eleitoral; as coligações partidárias; a implementação da cláusula de barreira que trata do período disponível para campanha em rádio e TV, de acordo com o fundo partidário; a periodicidade das eleições; o fim do sistema de reeleição; a alteração de voto obrigatório para voto facultativo; a duração dos mandatos; a idade mínima dos candidatos para posse dos cargos; o processo para suplência; e o ponto de estudo deste trabalho, que é o financiamento de campanha eleitoral.

Ao realizar um resgate histórico sobre o tema, nota-se que a Lei n 9.504/1997 permitia a doação de empresas e pessoas físicas para financiamento de campanhas eleitorais, respeitados os limites de $2 \%$ do faturamento anual das empresas e até $10 \%$ do rendimento bruto referente ao ano anterior para pessoas físicas.

O Supremo Tribunal Federal, em Ação Direta de Inconstitucionalidade julgada em 17 de setembro de 2015 (ADI 4.650), proibiu o financiamento de campanha eleitoral por empresas. O Ministro Relator Luiz Fux justificou a referida decisão nos seguintes termos: "A doação por pessoas jurídicas às campanhas eleitorais, antes de refletir eventuais preferências políticas, denota um agir estratégico destes grandes doadores, no afã de estreitar suas relações com o poder público, em pactos, muitas vezes, desprovidos de espírito republicano".

Os financiamentos clandestinos de campanha eleitoral no Brasil foram expostos à população por ocasião do julgamento do "Mensalão" e, mais recentemente, com os casos descobertos pela "Operação Lava-Jato", relacionados a inúmeras empresas que adotaram essas práticas em busca de

\footnotetext{
${ }^{29}$ Disponível em:<https://brasil.elpais.com/brasil/2017/08/11/politica/1502405203_433613. html>. Acesso em: 28 ago. 2017.
}

Resenha Eleitoral (Florianópolis), v. 22, n. 1-2, p. 77-106, 2018 
contratações futuras com o poder público, como a Odebrecht, OAS entre outras. Esses fatos influenciaram a referida decisão.

Outra questão que influenciou o referido julgamento foi o impacto das doações empresariais nas campanhas eleitorais, tornando-as injustas, pois asseguram uma divulgação ampla para os candidatos financiados e reduzem as chances daqueles que não têm relações com as empresas.

Diante deste cenário, foi editada a Lei no 13.165 , de 29 de setembro de 2015, que altera o sistema normativo eleitoral com o fim de reduzir os custos das campanhas eleitorais, simplificar a administração dos partidos políticos e promover a participação feminina.

Especificamente sobre o financiamento de campanha eleitoral, restrito às pessoas físicas, estabelece regras e possibilita que candidatos façam doações para outros ou, ainda, utilizem recursos próprios para financiar a campanha, até o limite dos gastos previstos em lei.

Com relação ao recebimento de valores provenientes de fontes não permitidas ou não identificadas, seja pelos candidatos ou pelo partido, estes devem devolver os valores ou, não sendo possível, transferi-los para a conta única do Tesouro Nacional ${ }^{30}$.

Bastaria a regra que somente permite a doação em dinheiro ou estimável de pessoas físicas. Mas a referida lei reafirma que permanece vedado o recebimento, direto ou indireto, de doação em dinheiro ou estimável, inclusive por meio de publicidade de qualquer espécie, procedente de entidade ou governo estrangeiro, órgão da administração pública, direta e indireta, ou fundação mantida com recursos provenientes do Poder Público, concessionário ou permissionário de serviço público, entidade de direito privado que receba, na condição de beneficiária, contribuição compulsória em virtude de disposição legal, entidade de utilidade pública, entidade de classe ou sindical, pessoa jurídica, sem fins lucrativos, que receba recursos do exterior, entidades beneficentes e religiosas, entidades esportivas, organizações não governamentais que recebam recursos públicos, organizações da sociedade civil de interesse público ${ }^{31}$.

Tal normatização foi corroborada pela Resolução $n^{0} 23.463$, de 15 de dezembro de 2015, do Tribunal Superior Eleitoral, que dispõe sobre a arrecadação e os gastos de recursos por partidos políticos e candidatos e sobre a prestação de contas nas eleições de 2016, com proibição acerca da doação por pessoas jurídicas.

\footnotetext{
${ }^{30}$ Artigo 24 da Lei no $13.165 / 2015$.

31 Artigo 24 da Lei no 9.504/1997.
} 
Evidente que os candidatos e partidos políticos sentiram os impactos de tais alterações, levando em consideração o custo das campanhas eleitorais, por isso, inauguraram discussões sobre novas formas de financiamento de campanhas eleitorais, como veremos a seguir.

\subsection{Proposta legislativa de financiamento público de campanha eleitoral}

A Comissão Especial para Análise, Estudo e Formulação de Proposições Relacionadas à Reforma Política (CEPOLITI), da Câmara dos Deputados, anteriormente mencionada, apresentou em 17 de agosto de 2017 a discussão acerca de seu $3^{\circ}$ relatório parcial, em conjunto com projeto de lei que propõe mudança significativa no modelo de financiamento de campanhas no Brasil ${ }^{32}$.

A proposta dispõe sobre o financiamento público de campanhas, tendo como seu centro a criação de um Fundo Especial para o Financiamento da Democracia (FFD), responsável pelo fornecimento de recursos públicos para todos os candidatos, sendo estes distribuídos e fiscalizados pela Justiça Eleitoral, no entanto, sem substituir o Fundo Partidário ${ }^{33}$.

Anteriormente, em 10 de agosto de 2017, a Comissão Especial rejeitou, por 20 votos contra 4, o destaque do Partido Socialismo e Liberdade (PSOL) que visava à exclusão do referido fundo especial. Pela proposta, $0,5 \%$ da receita corrente líquida seria destinado ao custeio do fundo. Estimou-se que seriam arrecadados, em 2018, cerca de três bilhões e seiscentos milhões de reais para essa atividade ${ }^{34}$.

Segundo estudo realizado pela Organização para Cooperação e Desenvolvimento Econômico (OCDE), cerca de 118 países contam com algum tipo de financiamento público para apoiar partidos ou campanhas eleitorais ${ }^{35}$.

32 Disponível em: <http://www2.camara.leg.br/camaranoticias/noticias/POLITICA/ 535104-REFORMA-POLITICA-RELATOR-ANTECIPA-SISTEMA-ELEITORAL-MISTO-PARA-2022.html>. Acesso em: 28 ago. 2017.

${ }^{33}$ Idem.

${ }^{34}$ Disponível em: < http://www2.camara.leg.br/camaranoticias/noticias/POLITICA/538901-COMISSAO-MANTEM-FUNDO-PUBLICO-PARA-FINANCIAR-CAMPANHAS-ELEITORAIS.html>. Acesso em:

${ }^{35}$ Disponível em: < http://www.oecd.org/governance/financing-democracy-9789264249455-en. htm>. Acesso em: 28 ago. 2017.

Resenha Eleitoral (Florianópolis), v. 22, n. 1-2, p. 77-106, 2018 
Essa espécie de financiamento, de forma exclusiva, exige a divisão proporcional entre os partidos, conforme os votos obtidos na última eleição para deputados federais, a fim se assegurar que os partidos maiores recebam mais dinheiro do que aqueles com menor representatividade, desde que exista um teto, a fim de evitar a perpetuação dos maiores partidos no poder (CAMPOS; ASSIS JUNIOR, 2012, p. 38-39).

Em princípio, diversas organizações internacionais apontam que o financiamento estatal é benéfico para diminuir a influência de empresas, entretanto, o mecanismo deve ser acompanhado de outras fontes de financiamento, como doações de cidadãos, além da necessária fiscalização severa ${ }^{36}$.

A definição por um modelo de financiamento de campanha eleitoral exclusivamente público ou privado não acabará com a corrupção, tampouco, com o financiamento clandestino ("caixa dois").

No primeiro modelo, bilhões de reais serão custeados pelos cofres públicos, enquanto a população não tem acesso real a saúde, educação, segurança pública, desporto, lazer e cultura. Mesmo assim, vantagens serão oferecidas aos candidatos, como o custeio de despesas pessoais, para obter futuras vantagens em contratos com a administração pública.

No segundo, com permissão ou não, as empresas financiarão as campanhas clandestinamente e exigirão a contrapartida após a eleição, tanto que financiam de forma lícita e muitas vezes ilícita, partidos com ideologias completamente diferentes e, ao mesmo tempo, concorrem ou pretendem concorrer para fornecer bens ou serviços para a administração pública, o que demonstra o claro interesse em obter vantagens futuras e indevidas.

Considerando esse cenário, somos favoráveis, com todas as ressalvas contra as mazelas desse sistema, ao financiamento privado de campanha eleitoral. Por isso, é preciso estabelecer os instrumentos adequados para assegurar a transparência na relação entre as empresas e os candidatos no pleito eleitoral e, posteriormente, com o governo.

\section{Considerações finais: diretrizes para o sistema preventivo de infrações penais eleitorais e contra a Administração Pública por empresas e candidatos}

Após a contextualização política e legislativa do cenário brasileiro contemporâneo, desponta como meta desta pesquisa a identificação dos

${ }^{36}$ Idem. 
modelos ou sistemas aplicáveis para prevenção das infrações penais relacionadas à corrupção, no período eleitoral e após as eleições a partir da diplomação dos candidatos eleitos.

É preciso romper com as condutas de alguns candidatos eleitos, embora não estimuladas, são supostamente legitimadas pelo povo por meio do pleito eleitoral, pela prestação de contas ineficiente e pela impunidade.

Assim, no presente capítulo, apresentamos mecanismos necessários para a lisura do processo eleitoral, a fim de assegurar a legitimidade e o cumprimento adequado dos mandatos, isto é, sem práticas corruptas e desleais. Consequentemente, alcançar resultados positivos para a sociedade brasileira.

\subsection{Mudança de cultura, transparência eleitoral, limites rígidos de gastos e controles eficientes}

A lisura de qualquer atividade depende de condutas leais, de limites claros, precisos e rígidos e, ainda, de controles efetivos. Quanto aos problemas identificados nesta pesquisa sobre o financiamento empresarial de campanha eleitoral, inúmeras medidas devem ser implementadas, com especial destaque para o necessário investimento em educação, a fim de propiciar às futuras gerações uma cultura intolerante com atos de corrupção, a observância aos regramentos da publicidade (transparência) e dos limites intransponíveis de gastos eleitorais para possibilitar o efetivo controle das atividades dos candidatos, partidos políticos, agentes eleitos e empresas doadoras.

Convém destacar o cenário brasileiro relacionado às medidas que devem ser implementadas.

É difícil admitir, mas a qualidade da educação no Brasil não avançou. Praticamente não há qualquer preocupação com uma formação ética e cidadã. As famílias no passado cumpriam esse papel, mas foram transformadas pelas aflições do mundo globalizado. Os pais convivem pouco com seus filhos, pois passam a maior parte do tempo imersos no trabalho, além do tempo que levam nos precários sistemas de transporte público ou no caótico trânsito das cidades brasileiras. Não há planejamento, tampouco, planos de impacto (real) dos empreendimentos no trânsito rodoviário.

Curiosamente, o efeito pedagógico que pode reduzir a tolerância à corrupção decorre das descobertas recorrentes dos delitos perpetrados por ocupantes dos mais elevados cargos da república brasileira e pelos detentores do poder econômico que administram as grandes empresas que 
operam no país, amplamente divulgados pela imprensa mundial e que resultaram nas prisões de pessoas que eram acobertadas pelo endêmico sistema de corrupção. Ao nosso ver, essa mudança decorre da renovação (iniciada em 1997) e valorização da Polícia Federal, cujos resultados são alcançados simplesmente por meio de atividades de inteligência que evitam o enfrentamento armado das organizações criminosas e conduzem às prisões dos referidos poderosos.

Assim, o Brasil começou, gradativamente, a engajar-se no combate à corrupção e a adotar iniciativas que levem à mudança cultural, a fim de promover condutas éticas e lícitas, nos setores público e privado.

O Tribunal Superior Eleitoral disciplinou, na Resolução n² 23.435, de 5 de fevereiro de 2015, questões relacionadas ao acesso à informação, e estabeleceu regramentos para garantir a maior transparência possível aos destinatários desses dados, isto é, a população brasileira.

Devem ser ampliados os investimentos em mecanismos que viabilizem, otimizem e estimulem a transparência das atividades praticadas em nome ou pelo governo, especialmente no que diz respeito ao processo eleitoral, limitando inclusive os gastos inerentes às atividades partidária e política, a fim de evitar o abuso do poder econômico, preservando, assim, o processo democrático de escolha dos representantes do povo.

Tal forma de controle e publicidade se reveste como prestação de contas à sociedade, tanto com relação aos processos e às peculiaridades previstas na legislação, quanto com relação ao dispêndio de recursos públicos para manter a máquina governamental em funcionamento.

O sistema de controle da justiça eleitoral integrado pela população que pode noticiar as infrações, a Polícia Federal que apura as infrações penais, o Ministério Público Eleitoral que recebe as notícias, demanda a Polícia para apurar os delitos e, por fim, propõe as ações civis e penais para obter um provimento perante à Justiça Eleitoral, que acumula o papel de jugar as contas dos candidatos e partidos ${ }^{37}$, é ineficaz.

${ }^{37}$ Lei no 9.504/1997: “Art. 30. A Justiça Eleitoral verificará a regularidade das contas de campanha, decidindo: I - pela aprovação, quando estiverem regulares; II - pela aprovação com ressalvas, quando verificadas falhas que não lhes comprometam a regularidade; III pela desaprovação, quando verificadas falhas que lhes comprometam a regularidade; IV - pela não prestação, quando não apresentadas as contas após a notificação emitida pela Justiça Eleitoral, na qual constará a obrigação expressa de prestar as suas contas, no prazo de setenta e duas horas". 
As atividades estão revestidas de extrema burocracia estabelecida no universo de leis e resoluções eleitorais, sem qualquer agilidade e eficiência na apuração das infrações.

O efetivo controle das atividades dos candidatos, partidos políticos, agentes eleitos e empresas doadoras depende, ainda, do estabelecimento de um modelo administrativo (sem a interferência do Poder Judiciário) de prestação e aprovação de contas eleitorais, cujas informações devem ser processadas conforme o rigoroso método de auditoria adotado pelas empresas, que preza pela fidedignidade dos registros financeiros e pelo cumprimento dos limites legais.

Caso os dados sejam inconsistentes, o Ministério Público deve acessar o Poder Judiciário por meio de ações de impugnação da candidatura ou de cassação do mandato. A Justiça Eleitoral deve ser demandada somente na hipótese de infração eleitoral, portanto, é preciso descentralizar a atividade de controle das contas, a fim de assegurar a celeridade processual e a desburocratização desse controle.

\subsection{Governo aberto}

Como anteriormente exposto, para trabalharmos em um sistema preventivo de infrações, sejam essas penais eleitorais ou funcionais após a diplomação, faz-se necessário estabelecer mecanismos de controle e transparência, que possibilitem que a população tenha acesso às informações relacionadas ao governo e aos recursos públicos.

Essa é uma das propostas da parceria para Governo Aberto (em inglês, Open Government Partnership - OGP), que é uma iniciativa internacional, com objetivo de difundir e incentivar globalmente práticas governamentais relacionadas à transparência dos governos, ao acesso à informação pública e à participação social ${ }^{38}$.

A OGP foi lançada em 20 de setembro de 2011, e o Brasil é um dos oito países fundadores da parceria ${ }^{39}$.

Como membro da OGP, o Brasil implementou inúmeras iniciativas de governo aberto, que estão em diferentes estágios. Algumas representam mudanças legais e administrativas com o propósito de aprimorar a gestão pública do país . Mesmo assim, ainda precisa estabelecer um regra-

38 Disponível em: <http://www.cgu.gov.br/assuntos/transparencia-publica/governo-aberto>. Acesso em: 28 ago. 2017.

${ }^{39}$ Idem.

Resenha Eleitoral (Florianópolis), v. 22, n. 1-2, p. 77-106, 2018 
mento legal claro e objetivo, para que a Administração Pública em geral, em todas as esferas, exerça um governo realmente aberto, a fim de assegurar o acesso à informação e o controle dos atos do poder público pelos titulares do poder - o povo brasileiro.

\subsection{Integridade empresarial (compliance)}

As empresas no Brasil, por influência legislativa e econômica estrangeira, passaram recentemente a se preocupar com a prevenção de infrações e o comportamento ético de seus colaboradores, uma vez que a má reputação pode gerar prejuízos irrecuperáveis e danos à imagem das empresas. Até mesmo grupos empresariais fortemente estruturados há anos podem ser levados à bancarrota.

Como destacado alhures, os resultados da ação penal 470 ("Mensalão"), que tramitou perante o Supremo Tribunal Federal, foram expostos pela mídia para demonstrar o abuso de poder dos mandatários políticos e de inúmeras empresas que os patrocinavam e se valiam dessa proximidade para obter vantagens econômicas indevidas, como contrapartidas, em prejuízo da lisura do processo democrático, do Estado e do povo brasileiro, agravando as crises política, econômica e moral.

A democracia brasileira foi prejudica pelos pleitos eleitorais viciados pelos atos de corrupção praticados por candidatos em coautoria com empresários, pois os resultados eleitorais foram influenciados pelos investimentos clandestinos e superiores aos oficialmente declarados.

O cenário empresarial brasileiro, influenciado pelos referidos resultados, pressionou o poder político para editar uma legislação que trate da corrupção no âmbito corporativo, o que resultou na aprovação e promulgação da Lei n⿳o 12.846 , de $1^{\circ}$ de agosto de 2013.

A chamada Lei Anticorrupção ou "Lei da empresa limpa" trouxe grande inovação ao ordenamento jurídico, dispondo pela primeira vez sobre a responsabilidade objetiva administrativa e civil das pessoas jurídicas que praticam infrações contra a administração pública, nacional ou estrangeira. Vale destacar que, a responsabilização da pessoa jurídica não exclui a responsabilidade individual de seus dirigentes ou administradores ou de qualquer pessoa natural, autora, coautora ou partícipe do ato ilícito (PETRELLUZZI; RIZEK JUNIOR, 2014, p. 51).

Dentre as infrações arroladas na supramencionada lei, encontra-se desde a prática de corrupção, seja em sua forma convencional ou pelo 
financiamento ou custeio da prática, bem como traz disposições acerca de infrações no tocante a licitações e contratos públicos.

A referida alteração legislativa impôs às corporações a obrigação de adotar medidas de conscientização a fim de modificar a cultura organizacional. Com isso, desenvolvem programas de integridade corporativa, considerando que o mercado brasileiro foi conivente por anos com práticas infracionais, cujas sanções são severas e muito arriscadas para as entidades privadas (NEGRÃO; PONTELO, 2014, p. 44).

O Decreto $\mathrm{n}^{\mathrm{9}}$ 8.420, de 18 de março de 2015, que regulamenta a Lei Anticorrupção, no artigo 41, define como programa de integridade no âmbito empresarial o:

Conjunto de mecanismos e procedimentos internos de integridade, auditoria e incentivo à denúncia de irregularidades e na aplicação efetiva de códigos de ética e de conduta, políticas e diretrizes com objetivo de detectar e sanar desvios, fraudes, irregularidades e atos ilícitos praticados contra a administração pública, nacional ou estrangeira.

Neste sentido, para atingir o público empresarial, incluindo seus colaboradores, fornecedores e prestadores, que, por vezes, compreende pessoas em diferentes localidades, culturas e realidades, faz-se necessária a implementação de programas de treinamento baseados em riscos, além de ações efetivas de endomarketing, para gerar a consciência necessária sobre a condução dos negócios de forma ética e em consonância com a legislação vigente.

Ademais, a existência de controles internos efetivos também se transformou em um importante pilar empresarial, uma vez que os procedimentos bem estruturados são claros e evitam desvios de conduta (NEGRÃO; PONTELO, 2014, p. 46).

Outro ponto diretamente ligado aos controles internos é a contratação de auditorias independentes, o que possibilita certificar que os procedimentos internos são os necessários para as atividades da empresa e que estes não possuem vulnerabilidades capazes de expô-la a riscos, sejam estes legais ou relacionados à sua imagem e capacidade de manter credibilidade perante o mercado.

Cabe ainda tratar das estruturas empresariais para descobrir as infrações executadas por seus colaboradores, clientes ou fornecedores. A principal porta de entrada das notícias de infrações é o denominado "canal de denúncias", que tem por objetivo viabilizar a comunicação entre as partes relacionadas com a empresa, para que aquelas possam trazer a 
conhecimento situações que estejam em desacordo com o ordenamento jurídico ou até mesmo em dissonância com os valores estabelecidos como fundamentos da empresa.

A efetividade desse canal de comunicação depende de treinamentos e campanhas internas de conscientização permanente, especialmente em países de origem latina, como o Brasil, que resistem à ideia de delatar o infrator, como se aquele que aponta a irregularidade fosse um traidor, mesmo sem qualquer pacto celebrado com o infrator.

O supramencionado canal de comunicação tem se mostrado como uma grande fonte de notícias e, portanto, uma importante ferramenta no meio corporativo para obter informações sobre condutas indevidas, que outrora só seriam levadas a conhecimento das organizações quando da realização de investigações oficiais, momento em que estas precisariam levantar detalhes, documentos e demais evidências como forma de defesa e não como de prevenção e apuração.

Neste sentido, outro ponto de investimento das grandes empresas diz respeito ao processo de investigações internas, com vistas a identificar as práticas infracionais, seus autores, os respectivos impactos na organização, bem como as providências administrativas e judiciais aplicáveis, possibilitando que as organizações, além de aplicarem as medidas disciplinares necessárias como advertência, suspensão e demissão, possam também requerer as medidas civis e penais para responsabilização e reparação dos danos (SILVEIRA; DINIZ, 2015, p. 345).

O que se demonstra de mais positivo neste contexto de alteração legislativa e do âmbito corporativo diz respeito à alteração na consciência empresarial sobre as formas de realizar e conduzir negócios e quanto isso traz de impactos positivos para a sociedade, que passará a ter desde prestadores de serviços a produtores e distribuidores atuando de forma legítima e honrosa, sem contar com artifícios ilícitos ou relações antiéticas para manter as atividades no mercado.

Desta forma, a legislação brasileira deve exigir a existência de programa de integridade para admitir o financiamento empresarial de campanha eleitoral, comprovado por registros de treinamentos periódicos dos colaboradores, de apoio da alta administração, por exemplo, por meio de discursos do presidente da companhia, de campanhas internas de conscientização, de efetividade do canal de "denúncias" de irregularidades, de eficiência dos controles internos, de contratação periódica de auditores inde- 
pendentes, e, por fim, de adoção de códigos de ética e de conduta, políticas e diretrizes, com objetivo de detectar e sanar desvios, fraudes, irregularidades e atos ilícitos praticados contra a administração pública.

\section{Referências}

BECK, Ulrich. Sociedade de risco: rumo a uma outra modernidade. Trad. Sebastião Nascimento. São Paulo: 34, 2010.

BONAVIDES, Paulo. Curso de direito constitucional. 24. ed. São Paulo: Malheiros, 2009.

. Teoria do estado. 6. ed. São Paulo: Malheiros, 2007.

CAMPOS, Hélio Silvio Ourém; ASSIS JUNIOR, Moises Pereira de. Financiamento público de campanhas eleitorais. Estudos eleitorais / Tribunal Superior Eleitoral, Brasília, v. 7, n. 2, p. 25-45, 2012.

CARAZZAI, Estelita Hass. Com caixa dois, doação oficial era bônus, segundo Marcelo Odebrecht. FOLHA DE S. PAULO, Curitiba, 12 abr. 2017. Poder. On-line.

CASTRO, Fabrício de. Gastos nas campanhas municipais de 2016 somam R $\$$ 2,131 bilhões, diz Gilmar Mendes. O ESTADO DE S. PAULO, São Paulo, 2 out. 2016. Política. On-line.

CORTELLA, Mario Sergio; BARROS FILHO, Clovis de. Ética é vergonha na cara! São Paulo: Papirus 7 Mares, 2014.

COSTA, Tito. Recursos em matéria eleitoral. 8. ed. São Paulo: Revista dos Tribunais, 2004.

GOMES, Suzana de Camargo. Crimes eleitorais. 4. ed. São Paulo: Revista dos Tribunais, 2010.

GONÇALVES, Luiz Carlos dos Santos. Crimes eleitorais e processo penal eleitoral. São Paulo: Atlas, 2012.

GONTIJO, Conrado Almeida Corrêa. O crime de corrupção no setor privado: estudo de direito comparado e a necessidade de tipificação do delito no ordenamento jurídico brasileiro. Dissertação (Mestrado) - Faculdade de Direito da Universidade de São Paulo, São Paulo, 2015.

MIRANDA, Jorge. Manual de direito constitucional. 8. ed. Coimbra: Coimbra, 2009. 
NEGRÃO, Célia Lima; PONTELO, Juliana de Fátima. Compliance, controles internos e riscos: a importância da área de gestão de pessoas. Brasília: Senac, 2014.

PETRELLUZZI, Marco Vinicio; RIZEK JUNIOR, Rubens Naman. Lei anticorrupção: origens, comentários e análise da legislação correlata. São Paulo: Saraiva, 2014.

PONTE, Antonio Carlos da. Crimes eleitorais. São Paulo: Saraiva, 2008.

SÁNCHEZ, Jesús-María Silva. A expansão do direito penal. 2. ed. Trad. Luiz Octavio de Oliveira Rocha. São Paulo: Revista dos Tribunais, 2011.

SILVA, Marco Antonio Marques da. Cidadania e democracia: instrumentos para a efetivação da dignidade humana. In: SILVA, Marco Antonio Marques da; Jorge Miranda, MIRANDA, Jorge (Coords.). Tratado luso-brasileiro da dignidade humana. 2. ed. São Paulo: Quartier Latin, 2009.

SILVEIRA, Renato de Mello Jorge; DINIZ, Eduardo Saad. Compliance, direito penal e lei anticorrupção. São Paulo: Saraiva, 2015.

TERENZI, Gabriela; URIBE, Gustavo; AZEVEDO, Rayanne. Custo de R\$ 5 bilhões faz eleições deste ano baterem recorde histórico. FOLHA DE S. PAULO, São Paulo, 30 nov. 2014. Poder. On-line.

Roberto Ferreira Archanjo da Silva - Professor dos Cursos de Graduação e Pós-Graduação em Direito da Pontifícia Universidade Católica de São Paulo (PUC-SP); Professor Titular da Faculdade de Direito de São Bernardo do Campo (FDSBC) - Autarquia Municipal; Professor Convidado do Curso de Pós-Graduação Lato Sensu - Especialização em Direito Processual Penal da Escola Paulista da Magistratura (EPM); Mestre e Doutor em Direito pela PUC-SP; Especialista em Direito Processual Penal pela EPM. 